\title{
Visual observing behavior in the squirrel monkey*
}

\author{
RICHARD H. HAUDE \\ University of A kron, Akron, Ohio 44325
}

and

\author{
OAKLEY S. RAY \\ Veterans Administration Hospital and University of Pittsburgh, Pittsburgh, Pennsylvania 15213
}

\begin{abstract}
Ten squirrel monkeys were tested to determine whether visual observing behavior could be measured using a technique developed for rhesus monkeys. The Ss engaged in visual observation of a set of projected color slides of other squirrel monkeys to an extent comparable with visual observation by rhesus monkeys. Significant differences in both mean cumulative viewing time and mean frequency of visual observing were found for the different visual incentive conditions used. Previous reports of a low level of visual attention by squirrel monkeys were not confirmed.
\end{abstract}

Experimental studies of visual observing behavior (curiosity, visual exploration) in nonhuman primates have been largely confined to macaques (Butler, 1965). Few systematic investigations of analogous behavior in squirrel monkeys have been reported. Glickman and Sroges (1966) have pointed out that tree-living primates, a category which includes squirrel monkeys, tend to engage in a great deal of visual observing behavior. However, several reports have indicated that squirrel monkeys show relatively little "curiosity" or visual investigative behavior compared with other primates (DuMond, 1968; Glickman \& Sroges, 1966).

Previous studies of visual exploration in squirrel monkeys have relied largely upon observational techniques (Rumbaugh, 1968), and there has been little systematic effort to compare Old World and New World monkeys using identical conditions and techniques. No study of visual attention in squirrel monkeys has used a direct measure of visual observing behavior, although techniques for so doing have been developed for use with Old World monkeys (Haude, Kruper, \& Patton, 1966).

That the methods and procedures used in studying visual observing behavior generally have been different for New World monkeys as compared with Old World monkeys may be viewed as an obstacle in the face of any effort to develop either an empirical basis for direct comparisons among species or a satisfactory theoretical account of visual exploration phenomena. Also, the possibility of meaningful comparisons between squirrel monkeys and Old World monkeys does not appear to be obstructed by fundamental differences in visual capacity (DeValois, 1971) or by large differentials in the function of visual signals as vehicles for social communication (Winter, 1968).

The present investigation represents an attempt to

*Support for this research was provided in part by Grant MH-08111 from the National Institutes of Health. Requests for reprints should be addressed to Richard $H$. Haude, Department of Psychology, University of Akron, Akron, Ohio 44325. broaden the empirical data base of visual observing behavior by studying squirrel monkeys using a measuring technique shown to be both sensitive and reliable for rhesus monkeys (Haude et al, 1966). The visual stimuli were projected color slides of squirrel monkeys. Similar stimuli using rhesus monkeys have been shown to be effective visual incentives for visual observing in rhesus monkeys (Haude \& Ray, 1967).

\section{METHOD}

\section{Subjects}

Ss were 10 experimentally naive feral male squirrel monkeys (Saimiri sciureus). The age range of the Ss was estimated to be 18-30 months on the basis of weight and dental eruption data reported by Long and Cooper (1968). Ss were acclimated to laboratory conditions for 6 weeks prior to testing.

\section{Apparatus}

Aluminum test chambers (59 x $56 \times 67 \mathrm{~cm}$ ID) previously used in a similar study (Haude \& Ray, 1967) were slightly modified for the present study. The chambers contained grid floors and translucent Plexiglas ceilings. Low-level white noise was presented through a speaker above the ceiling of each chamber.

A glass window $(2.5 \times 10.0 \mathrm{~cm})$ was fixed in one side of each chamber $40 \mathrm{~cm}$ above the grid floor and centered horizontally. Access to the window from inside the chamber was limited by three vertical baffles (one parallel with the window and two perpendicular to it on either side) extending from the ceiling to $2.5 \mathrm{~cm}$ below the lower edge of the window. The effect of the baffles created a vertical channel $(10 \times 10 \mathrm{~cm})$, open at the bottom, into which a $S$ had to insert its head to obtain access to the window.

Two beams of infrared light $(0.3 \mathrm{~cm}$ diam $)$ crossed the channel parallel with and centered horizontally across the window. The light beams activated two Knight photocell relays connected in series. The light beams were $2.5 \mathrm{~cm}$ apart; front and rear beams were $2.5 \mathrm{~cm}$ from the window and rear baffle, respectively.

The channel around the window provided a means for measuring the looking or observing behavior of Ss, since only by placing its head into the channel from below and, thus, interrupting the infrared light beams, could a $S$ look through the window. Counters and running time meters connected with the photocell relays recorded both frequency of observing and cumulative viewing time. 
Table 1

Group Mean Observing Behavior as a Function of Incentive Stimulus Duration (Rate of Slide Change)

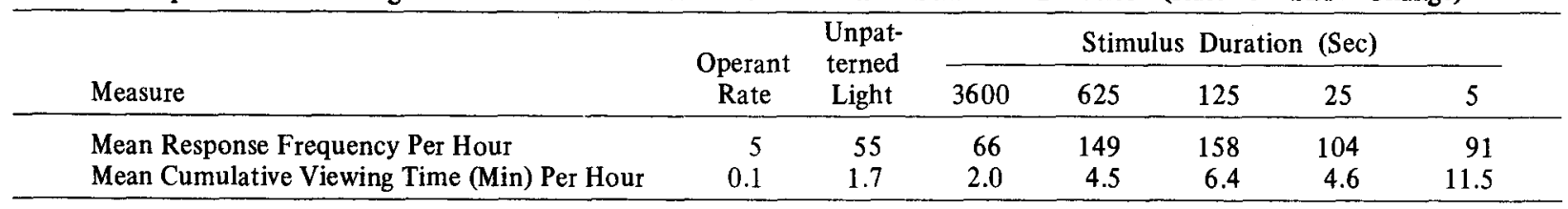

\section{Visual Incentives}

Visual incentive stimuli were projections of a set of 80 color $35-\mathrm{mm}$ slides of the Ss themselves. Slides showed groupings of one, two, or three animals $(27,27$, and 26 slides, respectively) and were taken at distances of 60,150 , and $300 \mathrm{~cm}$. The possible combinations of groupings and distances were randomized, as was the sequence of slides in the 80 -slide set. No attempt was made to analyze the behavioral content of the slides into specific categories. All the possible combinations of groupings and distances contained at least some slides showing one or more animals eating. Other slides showed one or more animals threatening the viewer, although none showed three animals all threatening the viewer. Some showed instances of aggression by one animal toward another, and many were presumably neutral in character, in that the animal or animals were shown directing their attention toward neither the viewer nor another animal.

A Kodak Carousel AV 900 projector projected the slides onto a $54 \times 69 \mathrm{~cm}$ screen placed $175 \mathrm{~cm}$ in front of the test chambers. The projected images exactly filled the screen. No lights other than the slide projector were present in the test room.

\section{Procedure}

All Ss were tested in the morning $1 \mathrm{~h}$ daily, 5 days per week. Ss were 19- to 22-h food deprived. Water was available ad lib except during testing.

On Days 1-5 all Ss were placed in the test chamber with the window covered on the outside by black insulation tape. Measures of the operant rate of insertions of the Ss' head into the vertical channel were obtained. On Days 6-10 the tape was removed, and unpatterned white light from the slide projector was presented. Frequency of looking (viewing) and cumulative viewing time were recorded. On Days $11-15$ a single randomly selected slide was projected each day for the entire test session (3600-sec rate of slide change).

For the remaining 4 weeks of testing (Days 16-35), Ss were presented with a single randomly selected slide (3600-sec rate) on Monday and Friday. On Tuesday, Wednesday, and Thursday, Ss were presented with slide change rates of $5,25,125$, or $625 \mathrm{sec}$. All Ss received only a single rate per week, and the order of different rates was randomly counterbalanced within Ss to control for possible order or sequence effects.

\section{RESULTS}

The group mean observing behavior per hour in terms of both response frequency and cumulative viewing time are shown for all visual incentive conditions in Table 1.

Analysis of variance for repeated measures of the same Ss was used to test for differences in both measures under all incentive conditions (operant rate, unpatterned light, and the five different rates of slide change). Differences among response frequencies were found to be significant $(F=3.79, \quad d f=6 / 54, p<.005)$. A Newman-Keuls test applied to the response frequency data indicated that the mean response frequency per hour in the operant rate condition was significantly different from mean response frequency under both the 125 -sec and 625 -sec rates of slide change. No other pairs of mean response frequencies were significantly different.

Significant overall differences in cumulative viewing times were also found $(F=4.18, d f=6 / 54, p<.005)$. A Newman-Keuls test of these data showed that the mean cumulative viewing time under the 5 -sec rate of slide change (11.5 min) was significantly different from mean cumulative viewing time under the operant rate, unpatterned light, and the 3600-, 625-, and $25-\mathrm{sec}$ rates of slide change $(0.1,1.7,2.0,4.5$, and $4.6 \mathrm{~min}$, respectively).

That relatively few comparisons between individual means reached significance indicates that the magnitude of inter-S variability was large. Significant differences between $\mathrm{Ss}$ were found for both measures $(F=5.40$, $\mathrm{p}<.001$ and $\mathrm{F}=3.60, \mathrm{p}<.005$ for response frequency and cumulative viewing time, respectively). However, in spite of rather large individual differences among Ss, the rank order of the Ss was highly stable for both measures under all incentive conditions. A Friedman two-way analysis of variance showed this stability across conditions to be highly significant $\left(\chi^{2} \mathrm{r}=29.00\right.$, $p<.001$ for response frequency and $\chi^{2} r=27.83$, $\mathrm{p}<.01$ for cumulative viewing time).

Finally, to determine whether either measure (response frequency or cumulative viewing time) was influenced by the sequence in which the various rates of slide change were presented, the data were analyzed by analysis of variance for repeated measures using sequence as the treatment effect. No significant differences in either response measure were found ( $F=0.69$ and $F=0.59$ for response frequency and cumulative viewing time, respectively). Between-S differences were again significant for both measures.

\section{DISCUSSION}

At least two implications of these data may be noted. First, under these conditions squirrel monkeys showed cumulative viewing time measures highly similar to those shown by rhesus monkeys under analogous conditions (Haude \& Ray, 1967). A comparison of the data for the respective species is shown in Table 2 . In both species, cumulative viewing time increases directly with an increase in the speed of slide change (decrease in 
Table 2

Group Mean Observing Behavior of Rhesus* and Squirrel Monkeys Compared

\begin{tabular}{|c|c|c|c|c|c|c|}
\hline \multirow[b]{2}{*}{ Measure } & & \multicolumn{5}{|c|}{ Rate of Slide Change (Sec) } \\
\hline & & 3600 & 625 & 125 & 25 & 5 \\
\hline \multirow{2}{*}{ Cumulative Viewing Time } & Squirrel Monkey & 2.0 & 4.5 & 6.4 & 4.6 & 11.5 \\
\hline & Rhesus Monkey & 2.4 & 3.8 & 4.8 & 6.7 & 12.0 \\
\hline \multirow{2}{*}{ Response Frequency } & Squirrel Monkey & 66 & 149 & 158 & 104 & 91 \\
\hline & Rhesus Monkey & 58 & 77 & 109 & 131 & 172 \\
\hline
\end{tabular}

*From Haude and Ray (1967).

stimulus duration). A single exception between the 125 -sec and 25-sec rates of slide change occurred for the squirrel monkeys. Response frequency measures for squirrel monkeys follow a pattern unlike that for response frequency measures in rhesus monkeys, with the highest frequency of observing occurring to the intermediate rates of slide change. This finding suggests that the cumulative viewing time measure may be a more reliable and sensitive indicator of visual investigative behavior and, therefore, the measure of choice, particularly in studies comparing two or more species in this regard. It is also conceivable that each measure reflects a different aspect of visual observing and that each should, therefore, continue to be obtained in further studies.

A further implication of the present study is that a comparative approach to visual observing phenomena may well be extended across both New World and Old World monkey species when emphasis is directed toward the use of comparable testing procedures. The present study has shown that a direct measure of visual observing by squirrel monkeys can be obtained by using a technique previously shown to be reliable in studying other species. Projected color slides are effective visual incentives for squirrel monkeys. It appears, therefore, that these procedures may be of value in investigating other aspects of visual observing such as social communication, visual deprivation, etc.

\section{REFERENCES}

Butler, R. A. Investigative behavior. In A. M. Schrier and H. F. Harlow (Eds.), Behavior of nonhuman primates. Vol. II. New York: Academic Press, 1965.

DeValois, R. L. Vision. In A. M. Schrier and F. Stollnitz (Eds.) Behavior of nonhuman primates. Vol. III. New York: Academic Press, 1971.

DuMond, F. V. The squirrel monkey in a seminatural environment. In L. A. Rosenblum and R. W. Cooper (Eds.), The squirrel monkey. New York: Academic Press. 1968.

Glickman, S. E., \& Sroges, R. W. Curiosity in zoo animals. Behaviour, 1966, 26, 151=188.

Haude, R. H., Kruper, D. C., \& Patton, R. A. Relationships among measures of visual exploration in monkeys. Journal of Comparative \& Physiological Psychology, 1966, 62, 156-159.

Haude, R. H., \& Ray, O. S. Visual exploration in monkeys as a function of visual incentive duration and sensory deprivation. Journal of Comparative \& Physiological Psychology, 1967, 64, 332-366.

Long, J. O., \& Cooper, R. W. Physical growth and dental eruption in captive-bred squirrel monkeys, Saimiri sciureus (Leticia, Columbia). In L. A. Rosenblum and R. W. Cooper (Eds.), The squirrel monkey. New York: Academic Press, 1968.

Rumbaugh, D. M. The learning and sensory capacities of the squirrel monkey in phylogenetic perspective. In L. A. Rosenblum and $R$. W. Cooper (Eds.), The squirrel monkey. New York: Academic Press, 1968.

winter, $P$. Social communication in the squirrel monkey. In $L$. A. Rosenblum and R. W. Cooper (Eds.), The squirrel monkey. New York: Academic Press, 1968.

(Received for publication January 2,1974 ; revision received March $6,1974$. ) 